02

\title{
Аннигиляционная замедленная флуоресценция индола и карбазола в жидких растворах при комнатной температуре
}

\author{
(C) А.А. Суходола \\ Институт фризики им. Б.И. Степанова НАН Беларуси, \\ 220072 Минск, Беларусь \\ e-mail: sukhodola@imaph.bas-net.by
}

Поступила в редакцию 06.07.2018 г.

\begin{abstract}
Измерены спектры длительной люминесценции индола и карбазола в нейтральном растворителе циклогексане и полярном этаноле. Спектры длительной люминесценции индола в этих растворителях имеют длинноволновой сдвиг относительно спектров флуоресценции. Спектры длительной люминесценции карбазола в обоих растворителях совпадают со спектрами флуоресценции. Длительное свечение индола интерпретировано как аннигиляционная замедленная флуоресценция (АЗФ) димеров, а длительное свечение карбазола - как АЗФ мономеров. Предполагается, что образование димеров индола происходит за счет диполь-дипольных взаимодействий молекул в возбужденном синглетном и основном состояниях, образующихся в результате триплет-триплетной аннигиляции. Измерена кинетика АЗФ и сделаны оценки времени жизни триплетных состояний индола в циклогексане. Установлено, что время жизни определяется процессами тушения триплетных состояний молекулами в основном состоянии. Константа скорости самотушения равна $6.2 \cdot 10^{7} \mathrm{M}^{-1} \mathrm{~s}^{-1}$.
\end{abstract}

DOI: $10.21883 /$ OS.2019.02.47195.195-18

\section{Введение}

Триптофан является одним из аминокислотных остатков в белках, который имеет спектры поглощения в ближней ультрафиолетовой области. Интерес к изучению фотофизических свойств этих молекул связан с доминирующим вкладом триптофана в люминесценцию белков, а также сильной зависимостью спектров флуоресценции и других фотофизических характеристик триптофана от свойств среды [1]. Триптофан является производным индола, замещенным в положении $C_{3}$.

Триплетные состояния триптофана играют важную роль в изучении структуры и медленной внутримолекулярной динамики белков [2,3]. Это связано с зависимостью времени жизни триплетных состояний триптофана в белках от микроокружения хромофора и структурнодинамического состояния белка. Для выяснения влияния микроокружения на свойства триплетных состояний в белках важно изучение механизмов свечения, связанных с триплетными состояниями, и определение путей дезактивации этих состояний для производных индола в жидких растворах.

В жидких растворах при комнатной температуре в условиях лазерного возбуждения молекул существенным каналом дезактивации триплетных состояний является триплет-триплетная аннигиляция (ТТА), которая происходит при диффузионном столкновении двух молекул в триплетном состоянии [4]. Если в результате ТТА образуются молекулы в возбужденном синглетном состоянии, то наблюдается аннигиляционная замедленная флуоресценция (АЗФ). Поскольку возбужденные синглетные состояния образуются при столкновении двух молекул в триплетном состоянии, в спектре АЗФ могут наблюдаться полосы мономерной и димерной (либо эксимерной) флуоресценции [5]. Спектр мономерной АЗФ совпадает со спектром быстрой флуоресценции. Спектр димерной АЗФ смещен в длинноволновую сторону [5]. Время затухания АЗФ определяется временем жизни триплетных состояний.

АЗФ в жидких растворах вследствие высокой скорости диффузии, как правило, является достаточно интенсивной и может служить источником информации о триплетных состояниях сложных молекул. В жидких растворах АЗФ впервые была обнаружена для пирена в этаноле в 1963 г. [5]. При возбуждении молекул в полосе поглощения пирена $\left(\lambda_{\mathrm{ex}}=366 \mathrm{~nm}\right)$ в спектре АЗФ наблюдались две полосы, принадлежащие мономерам и эксимерам.

АЗФ производных индола в жидких растворах изучена недостаточно. Ранее была исследована АЗФ индола и его производных в водных растворах при комнатной температуре [6]. В настоящей работе проведено изучение АЗФ индола и карбазола в полярном (этанол) и неполярном (циклогексан) растворителях. Цель работы - исследование механизмов АЗФ и определение путей релаксации триплетных состояний.

\section{Методика эксперимента}

Измерения проводились на автоматизированном лазерном спектрометре, позволяющем регистрировать кинетику люминесценции для разных длин волн спектра, а также спектры люминесценции на разных стадиях затухания свечения в микро- и миллисекундном диапазонах времен. В качестве возбуждающего излучения использовались импульсы третьей гармоники лазера на сапфире с 
титаном ( $\mathrm{Sa}: \mathrm{Ti})$ длительностью $20 \mathrm{~ns}$, перестраиваемого в спектральной области 250-300 nm. Накачка титансапфирового лазера осуществлялась импульсами второй гармоники лазера на YAG: $\mathrm{Nd}^{3+}$. Энергия возбуждающего импульса изменялась в области от 10 до $100 \mu \mathrm{J}$. Изначально регистрировалась кинетика люминесценции фотоэлектрическим методом с помощью АЦП в узком спектральном диапазоне, выделяемом монохроматором МДР-23. Для регистрации мгновенных спектров длительной люминесценции измерялось значение интенсивности свечения на определенном участке кинетической кривой. Запись спектра производилась путем сканирования по длинам волн регистрации. При измерении спектров флуоресценции, длительность которой значительно меньше временного разрешения установки, сигнал люминесценции интегрировался по времени. Спектры поглощения измерялись на спектрофотометре Cary-500.

Индол и карбазол фирмы Aldrich (Германия) очищались методом рекристаллизации из раствора в этаноле. Удаление кислорода до конечной концентрации $10^{-4}$ Torr осуществлялось вакуумированием по стандартной методике: 5-6 циклов замораживание-откачка.

\section{Результаты и обсуждение}

При возбуждении растворов исследуемых молекул наносекундными лазерными импульсами наблюдалась длительная люминесценция, затухающая в микросекундном временном диапазоне. Типичная кинетика длительной люминесценции показана на рис. 1 для обескислороженного раствора индола в циклогексане. Дополнительно на этом рисунке показана фоновая люминесценция неоткачанного раствора, которая определяется затуханием интенсивной быстрой флуоресценции, а также свечением кюветы. Из рис. 1 видно, что после $50 \mu \mathrm{s}$ фоновая люминесценция близка к нулю, и измеряемая люминесценция относится к длительному свечению исследуемых молекул. Тушение кислородом означает, что данное длительное свечение связано с триплетными состояниями. Для всех исследуемых молекул интенсивность длительной люминесценции была пропорциональна квадрату интенсивности возбуждающего излучения, что указывает на бимолекулярный характер свечения. Поскольку это свечение связано с триплетными состояниями, можно предположить, что возбужденные состояния, ответственные за длительную люминесценцию, образуются в результате триплет-триплетной аннигиляции (ТТА), а данное длительное свечение является АЗФ.

Спектры АЗФ, измеренные через $100 \mu$ s после возбуждающего импульса, а также спектры поглощения и флуоресценции индола и карбазола в разных растворителях приведены на рис. 2 и 3 соответственно. Необходимо отметить, что спектры АЗФ не зависели от концентрации раствора, длины волны возбуждающего излучения и момента их регистрации на кривой затухания.

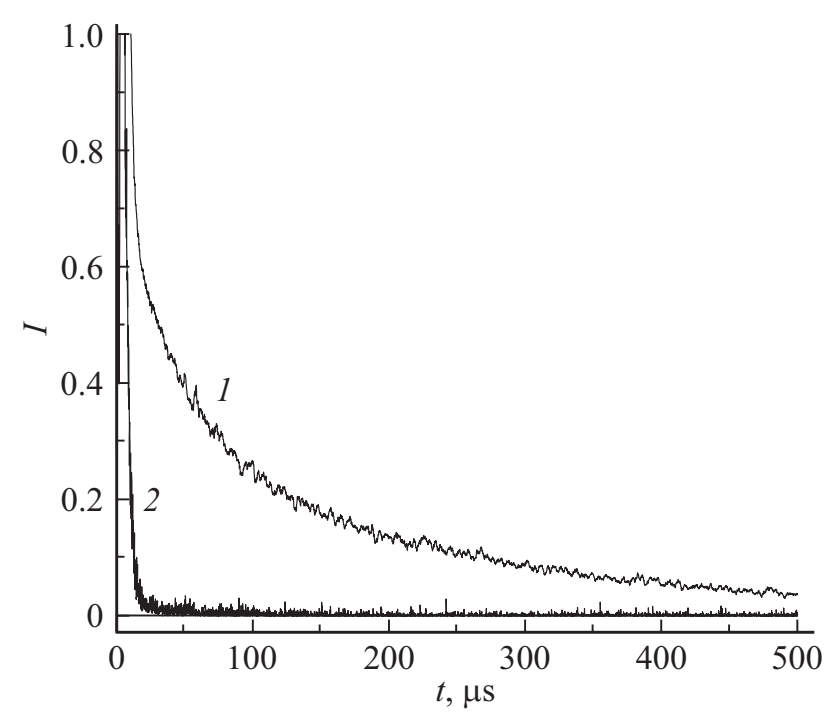

Рис. 1. Кинетика длительной люминесценции обескислороженного (кривая 1) и необескислороженного (кривая 2) растворов индола в циклогексане, $\lambda_{\mathrm{ex}}=280 \mathrm{~nm}, \lambda_{\text {reg }}=340 \mathrm{~nm}$. Концентрация раствора $C=4.0 \cdot 10^{-5} \mathrm{M}$.

Из рис. 2 и 3 (кривая 1) видно, что спектры поглощения индола и карбазола слабо зависят от растворителя. Небольшой длинноволновой сдвиг полосы поглощения в этаноле связан с образованием водородной связи молекул хромофора с молекулами растворителя [7]. Необходимо отметить также, что длинноволновая полоса поглощения этих молекул обусловлена переходами из основного состояния $S_{0}$ в возбужденное синглетное состояние $L_{b}$ [7].

Спектры флуоресценции индола и карбазола в циклогексане близки по своим характеристикам. Они является структурными и зеркально симметричными полосе поглощения $S_{0} \rightarrow L_{b}$. Это означает, что у молекул индола и карбазола в циклогексане излучающим является уровень $L_{b}$. Однако спектры флуоресценции этих молекул в полярном растворителе этаноле существенно отличаются. Для индола в этаноле спектр флуоресценции является широким, бесструктурным и имеет большой стоксов сдвиг, тогда как спектр флуоресценции карбазола является структурным и зеркально симметричным спектру поглощения. В работе [8] показано, что причиной такого различия является разное значение величины дипольного момента $\mu$ этих молекул в возбужденном синглетном состоянии. По данным работы [8] дипольный момент индола $\mu \sim 5 \mathrm{D}$, карбазола $\mu \sim 1.5 \mathrm{D}$. У индола высоким значением дипольного момента обладает $L_{a}$ состояние, уровень энергии которого лежит несколько выше уровня $L_{b}$. Предполагается, что индол в возбужденном синглетном состоянии образует с молекулами полярного растворителя комплексы благодаря дипольдипольному взаимодействию. Данное взаимодействие приводят к диэлектрической релаксации и большому смещению уровня энергии $L_{a}$-состояния [8-11]. В ре- 

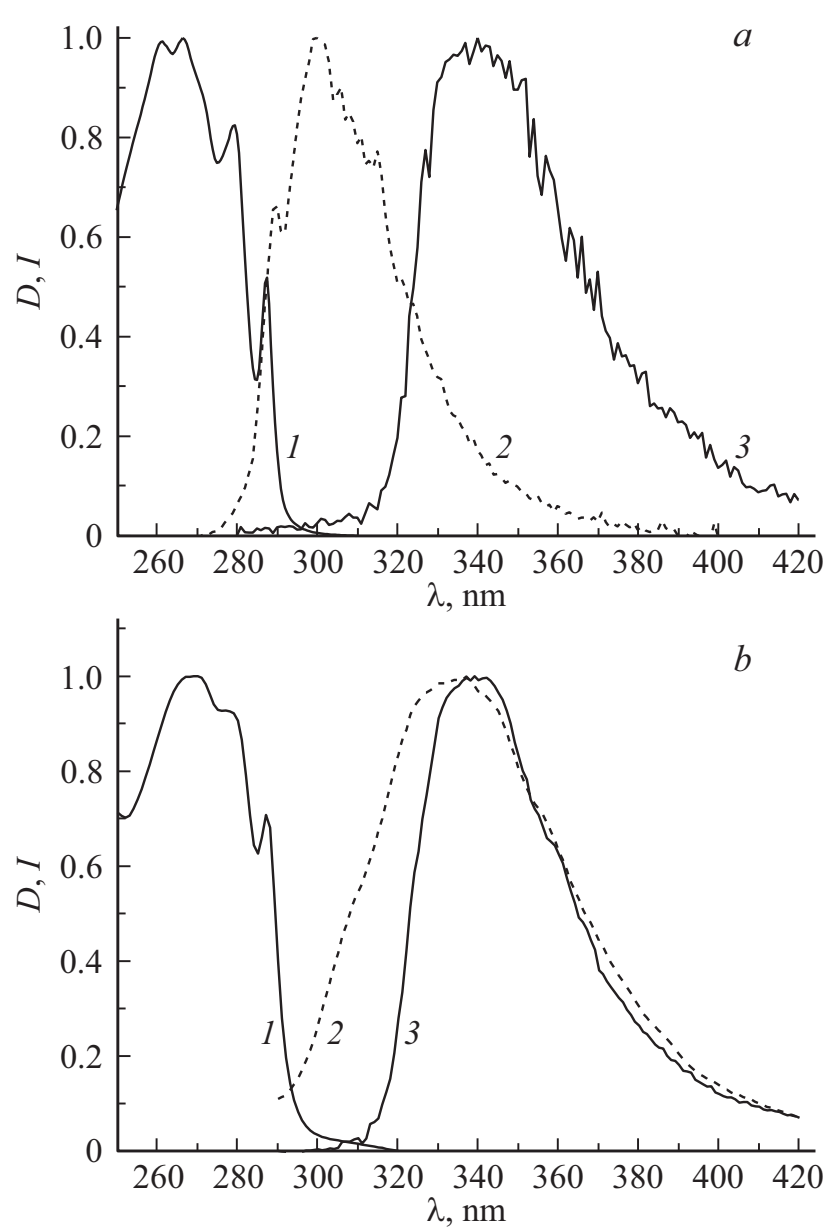

Pис. 2. Спектры поглощения (1), флуоресценции (2) и АЗФ, измеренные через $100 \mu$ s после возбуждающего импульса (3) раствора индола в циклогексане $a$ и этаноле $b, \lambda_{\mathrm{ex}}=280 \mathrm{~nm}$. Концентрация раствора $C=4.0 \cdot 10^{-5} \mathrm{M}$.

зультате $L_{a}$ становится нижним излучающим состоянием индола в этаноле. Потеря структуры в спектре флуоресценции является следствием высокой степени неоднородного уширения из-за большого увеличения дипольного момента в возбужденном синглетном состоянии [11]. У карбазола в этаноле нижним излучающим является $L_{b}$-состояние.

Спектры АЗФ индола и карбазола существенно отличаются по своим характеристикам. Спектры АЗФ индола в циклогексане и этаноле близки между собой, имеют значение максимума $\lambda_{\max }$ в районе $340 \mathrm{~nm}$ и не совпадают со спектрами флуоресценции в этих растворителях. Спектр АЗФ индола в циклогексане сдвинут в длинноволновую сторону относительно спектра флуоресценции на $40 \mathrm{~nm}$. Спектр АЗФ индола в этаноле находится в том же диапазоне, что и спектр флуоресценции, однако он имеет существенно меньшую полуширину. В отличие от индола спектры АЗФ карбазола в обоих растворителях совпадают со спектрами флуоресценции.

Для объяснения полученных результатов рассмотрим механизм образования возбужденных синглетных состояний при ТТА. Согласно механизму ПаркераСтивенса [12] (схема), в жидких растворах органических соединений при комнатной температуре ТТА происходит при диффузионном столкновении двух молекул в триплетном состоянии, в результате которого образуется комплекс из молекул в возбужденном синглетном и основном состояниях. Эти молекулы находятся в непосредственной близости друг от друга в клетке растворителя и могут взаимодействовать между собой с образованием возбужденных димеров и последующим испусканием димерной флуоресценции либо диссоциировать на молекулы в возбужденном синглетном и основном состояниях с последующим испусканием мономерной флуоресценции:

$$
\begin{gathered}
T_{1}+T_{1} \rightarrow\left(S_{1} S_{0}\right) \rightarrow D^{*} \rightarrow h v_{D}+2 S_{0}, \\
\downarrow \\
S_{1}+S_{0} \rightarrow h v_{M}+2 S_{0} . \\
\text { Схема }
\end{gathered}
$$

Спектр флуоресценции димеров сдвинут в длинноволновую сторону относительно спектра флуоресценции мономеров [12]. Наблюдаемый в эксперименте (рис. 2, кривая 3) длинноволновый сдвиг спектра АЗФ индола в циклогексане относительно спектра быстрой флуоресценции позволяет предположить, что данное длительное свечение обусловлено флуоресценцией димеров, образующихся в результате ТТА, и, следовательно, длительную люминесценцию индола в циклогексане можно идентифицировать как АЗФ димеров.

Следует отметить, что быстрая флуоресценция индола в циклогексане в разбавленных растворах при комнатной температуре обусловлена свечением мономеров. Полоса димеров в спектре флуоресценции не наблюдалась. Это связано с тем, что за время жизни молекулы в возбужденном синглетном состоянии не сталкиваются с собственными молекулами, а димеры в основном состоянии не образуются, поскольку энергия связи димеров при комнатной температуре меньше чем $k T$, где $k$ - постоянная Больцмана, $T=293$ К. Однако полоса флуоресценции возбужденных димеров с $\lambda_{\max } \sim 340 \mathrm{~nm}$ наблюдалась ранее для индола в 2-метилпентане при понижении температуре до $160 \mathrm{~K}$ [13].

Спектр АЗФ индола в этаноле имеет большой длинноволновой сдвиг относительно спектра поглощения и практически совпадает со спектром АЗФ индола в циклогексане. Это означает, что длительное свечение индола в этаноле также можно идентифицировать как АЗФ димеров, хотя спектр АЗФ индола в этаноле близок по положению к спектру быстрой флуоресценции. Причиной близкого положения этих спектров может быть большой стоксов сдвиг спектра быстрой флуоресценции за счет образования комплекса хромофора с молекулами полярного растворителя этанола. Длинноволновый сдвиг спектра АЗФ димеров происходит за счет образования комплекса индола в возбужденном состоянии с собственными молекулами в основном состоянии. 
Спектры АЗФ карбазола в циклогексане и этаноле совпадают со спектром быстрой флуоресценции, и, следовательно, длительное свечение карбазола в этих растворителях можно идентифицировать как АЗФ мономеров. Различие в механизмах АЗФ близких по классу молекул индола и карбазола можно также объяснить различием значений дипольных моментов этих молекул в возбужденном синглетном состоянии. Образующиеся в результате ТТА комплексы из молекулы индола в возбужденном синглетном и основном состояниях могут образовывать димеры за счет диполь-дипольных взаимодействий. Для карбазола энергии диполь-дипольных взаимодействий недостаточно для образования димеров, и они диссоциируют на молекулы в возбужденном синглетном и основном состояниях.

Из схемы 1 видно, что для молекул индола возможна также диссоциация столкновительного комплекса на молекулы в возбужденном синглетном и основном состояниях с последующим испусканием мономерной флуоресценции. Отсутствие АЗФ мономеров индола означает, что образующиеся в результате ТТА молекулы в возбужденном синглетном состоянии имеют низкий квантовый выход флуоресценции. Ранее было показано, что при
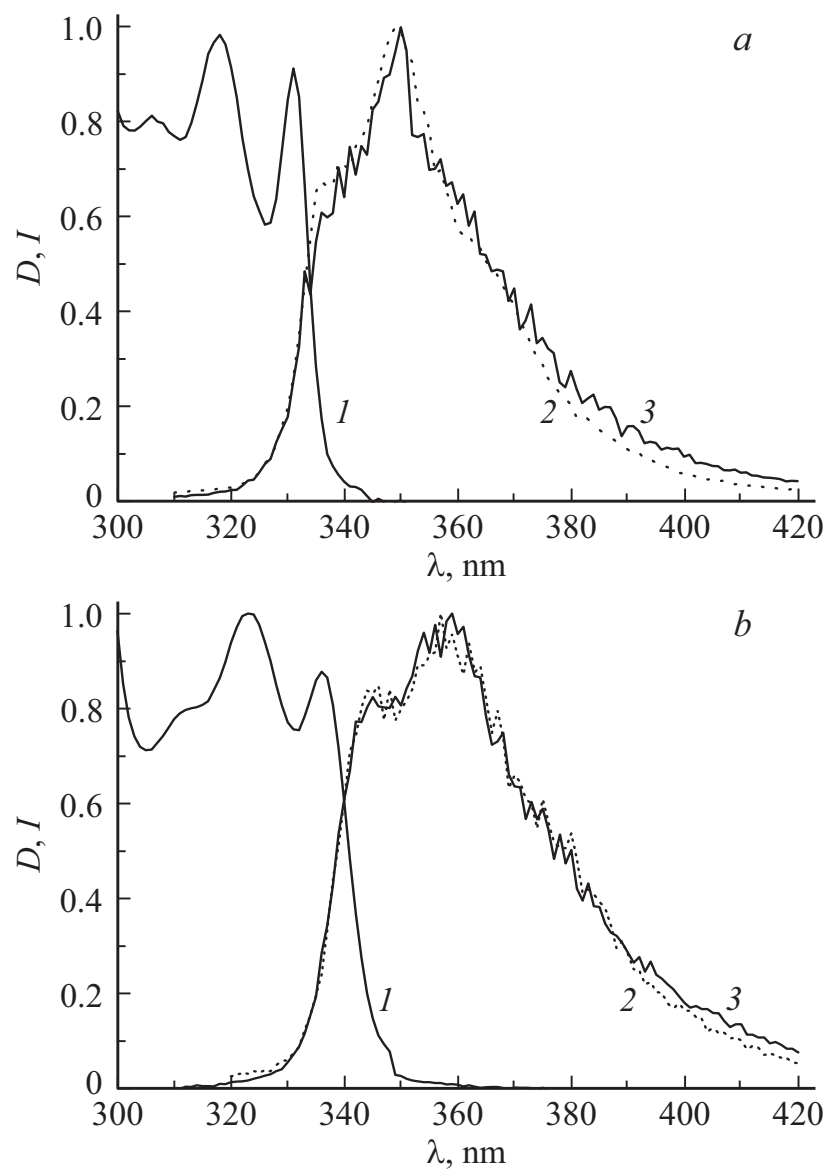

Pис. 3. Спектры поглощения (1), флуоресценции (2) и АЗФ, измеренные через $100 \mu \mathrm{s}$ после возбуждающего импульса (3) раствора карбазола в циклогексане $a$ и этаноле $b, \lambda_{\mathrm{ex}}=280 \mathrm{~nm}$. Концентрация раствора $C=2.5 \cdot 10^{-5} \mathrm{M}$.
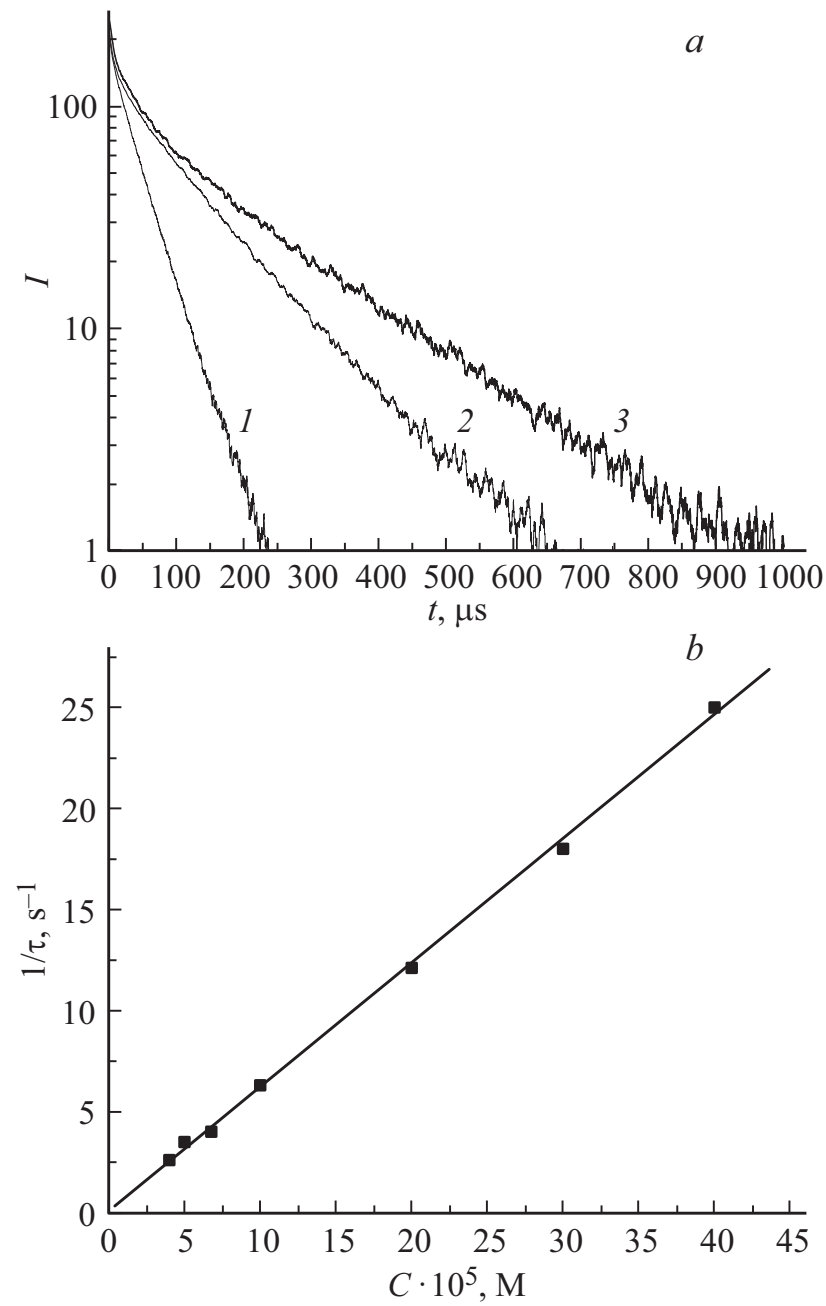

Рис. 4. Кинетика АЗФ индола в циклогексане при разной концентрации раствора $C=4.0 \cdot 10^{-4}(1), 1.2 \cdot 10^{-4}(2)$, $4.0 \cdot 10^{-5} \mathrm{M}(3): \lambda_{\mathrm{ex}}=280, \lambda_{\mathrm{reg}}=340 \mathrm{~nm}(a)$. Зависимость величины обратного времена жизни триплетных состояний от концентрации раствора индола в циклогексане $(b)$.

возбуждении молекул индола в нейтральных растворителях в высокие синглетные состояния квантовый выход флуоресценции резко уменьшается [14]. Аннигиляция триплетных состояний равносильна возбуждению молекул излучением с длиной волны $\lambda_{\mathrm{ex}} \sim 202 \mathrm{~nm}$, поскольку энергия возбужденного синглетного состояния, образующегося при ТТА, равна удвоенной энергии триплетных состояний $E_{T}\left(E_{T} \sim 24800 \mathrm{~cm}^{-1}[15]\right)$. Возможно также, что столкновительный комплекс (вследствие сильных диполь-дипольных взаимодействий) имеет низкую вероятность распада на отдельные молекулы в возбужденном синглетном и основном состояниях.

Кинетика АЗФ определяется процессами релаксации триплетных состояний. В данной работе кинетика АЗФ изучалась для раствора индола в циклогексане. На рис. 4, $a$ представлена кинетика АЗФ индола в циклогексане при разной концентрации раствора. Видно, что скорость затухания АЗФ растет с увеличением 
концентрации молекул хромофора. Кинетические кривые являются неэкспоненциальными на начальном участке и близки к экспоненте на конечном этапе затухания. Неэкспоненциальность этих кривых означает, что затухание триплетных состояний при используемых интенсивностях возбуждающего излучения определяется как мономолекулярными релаксациями, так и бимолекулярными процессами ТТА.

Время жизни триплетных состояний можно определить из анализа кинетики АЗФ. Оно равно удвоенному времени затухания АЗФ на экспоненциальном участке кривой. Измеренные этим методом времена жизни триплетных состояний зависят от концентрации раствора. При концентрации $C=4 \cdot 10^{-5} \mathrm{M} \tau \sim 400 \mu \mathrm{s}$. Это значение более чем на порядок выше $\tau$ для производных индола в жидких растворах, измеренных методом флеш-фотолиза. Однако при более высоких концентрациях раствора $C=4 \cdot 10^{-4} \mathrm{M}$ значение $\tau \sim 40 \mu \mathrm{s}$ соизмеримо с $\tau \sim 16 \mu \mathrm{s}$, полученным методом флешфотолиза [16], при той же концентрации раствора. Таким образом, возможной причиной низких значений времени жизни триплетных состояний, определенных методом флеш-фотолиза, является измерение кинетики триплеттриплетного поглощения при высоких концентрациях растворов.

Зависимость скорости затухания АЗФ от концентрации раствора означает, что время жизни молекул в триплетном состоянии определяется тушением собственными молекулами в основном состоянии. В общем случае константа скорости релаксации триплетных состояний $k$ будет определяться суммой констант скоростей мономолекулярного затухания $k_{1}$, ТTA $k_{2}$ и константы скорости самотушения $k_{T}$ :

$$
k=k_{1}+k_{2} C_{T}+k_{T} C,
$$

где $C$ - концентрация молекул индола, $C_{T}-$ концентрация молекул в триплетном состоянии. Поскольку на экспоненциальном участке кривой процессы концентрационного тушения триплетных состояний преобладают над процессами мономолекулярного затухания и ТТА, можно предположить, что

$$
k_{1}+k_{2} C_{T} \ll k_{T} C \text {. }
$$

Тогда из (2) и (1) следует, что $k=k_{T} C$ или

$$
1 / \tau=k_{T} C
$$

Из формулы (3) можно определить константу скорости самотушения $k_{T}$. Зависимость обратного времени жизни триплетных состояний от концентрации раствора приведена на рис. 4, $b$. Из рисунка видно, что она является линейной. Константа скорости самотушения $k_{T}$, определенная из этой зависимости, равна $k_{T}=6.2 \cdot 10^{7} \mathrm{M}^{-1} \mathrm{~s}^{-1}$. Эта величина имеет тот же порядок, что и $k_{T}$ для водных растворов индола, полученная в [17].
Как указывалось выше, время жизни триплетных состояний индола в циклогексане при концентрации раствора $C=4 \cdot 10^{-5} \mathrm{M}$ составляет $\tau \sim 400 \mu \mathrm{s}$. Чувствительность спектрометра не позволила измерить $\tau$ при более низких концентрациях молекул. Если предположить, что при концентрациях меньше чем $C=4 \cdot 10^{-5} \mathrm{M}$ время жизни молекул в триплетном состоянии будет определяться процессами самотушения, то экстраполируя зависимость $1 / \tau$ от $C$ на более низкие значения $C \sim 10^{-6} \mathrm{M}$, получим $\tau \sim 10 \mathrm{~ms}$. Эта величина близка к значению $\tau$ для водных растворов индола, измеренному в работе [17] при той же концентрации. Таким образом, можно предположить, что собственное время жизни триплетных состояний индола в жидких растворах при комнатной температуре находится в миллисекундном временном диапазоне.

Ранее было показано [18], что время жизни триплетных состояний $\tau$ триптофана в белках при комнатной температуре зависит от вязкости микроокружения. При плотном микроокружении триптофанилов, находящихся внутри белковой глобулы, оно составляет несколько секунд. Для триптофанилов, находящихся на периферии глобулы и частично экспонированных в растворитель, время жизни уменьшается до $0.2 \mathrm{~ms}$ [18]. Данные исследования показывают, что уменьшение $\tau$ фосфоресценции белков до $0.2 \mathrm{~ms}$ не связано с низкой вязкостью микроокружения и может быть обусловлено тушащим действием молекулярных групп, окружающих триптофан.

\section{Заключение}

На основании изучения спектральных характеристик длительной люминесценции жидких растворов индола и карбазола в циклогексане и этаноле при комнатной температуре установлено, что длительное свечение индола обусловлено АЗФ димеров, образующихся в результате ТТА, а длительное свечение карбазола АЗФ мономеров. Различие в механизмах АЗФ близких по классу соединений индола и карбазола объясняется различием значений дипольных моментов этих молекул в возбужденном синглетном состоянии. Предполагается, что образующиеся в результате ТТА комплексы из молекул индола в возбужденном синглетном и основном состояниях могут образовывать димеры за счет диполь-дипольных взаимодействий. Для карбазола энергии диполь-дипольных взаимодействий недостаточно для образования димеров, и они диссоциируют на молекулы в возбужденном синглетном и основном состояниях.

Кинетика затухания АЗФ индола в циклогексане зависит от концентрации раствора, а время жизни триплетных состояний определяется процессами тушения собственными молекулами в основном состоянии. При $C=4 \cdot 10^{-5} \mathrm{M} \tau \sim 400 \mu \mathrm{s}$. Измеренная из зависимости $1 / \tau$ от $C$ константа скорости самотушения равна $6.2 \cdot 10^{7} \mathrm{M}^{-1} \mathrm{~s}^{-1}$. 


\section{Список литературы}

[1] Демченко А.П. Люминесценция и динамика структуры белков. Киев: Наукова думка, 1988. 278 с.

[2] Мажуль В.М., Зайцева Е.М., Щербин Д.Г. // Биофизика. 2000. T. 45. C. 965.

[3] Махулл В.М., Ермолаев Ю.С., Конев С.В. // Журн. прикл. спектр. 1980. Т. 32. С. 903.

[4] Bohne C., Abuin E.B., Scaiano J.C. // J. Am. Chem. Soc. 1990. V. 112. P. 4226

[5] Parker C.A., Hatchard C.G. // Trans. Faraday Soc. 1963. V. 59. P. 284.

[6] Суходола А.А. // Журн. прикл. спектр. 2017. Т. 84. С. 551.

[7] Черницкий E.A. Люминесценция и структурная лабильность белков в растворе и клетке. Минск: Наука и техника, 1972. $280 \mathrm{c}$.

[8] Mataga N., Torihashi Y., Ezumi K. // Theoret. Chim. Acta. 1964. V. 21. P. 158.

[9] Lami H., Glasser N. // J. Chem. Phys. 1986. V. 84. C. 597.

[10] Vincent M., Gallay J., Demchenko A.P. // J. Phys. Chem. 1995. V. 99. P. 14931-14941.

[11] Callis P.R. // Methods in Ezymology. 1997. V. 278. P. 113.

[12] Паркер С. Фотолюминесценция растворов. М.: Мир, 1972. $510 \mathrm{c}$.

[13] Andrews L.J., Forster L.S. // Photochem. Photobiol. 1974. V. 19. P. 353.

[14] Tatischeff I., Klein R. // Photochem. Photobiol. 1975. V. 22. P. 221.

[15] Ilich P. // J. Mol. Struct. 1995. V. 354. P. 37.

[16] Pernot C., Lindquist L. // J. Photochem. 1976/1977. V. 6. P. 215.

[17] Strambini G.B., Kerwin B.A., Mason B.D., Gonnelli M. // Photochem. Photobiol. 2004. V. 80. P. 462.

[18] Strambini G.B., Gonnelli M. // Biochemistry. 1995. V. 34. P. 13847. 